\title{
Reading about deception
}

\author{
Sean A. Spence ${ }^{1}$
}

The Psychiatrist (2010), 34, 146-149, doi: 10.1192/pb.bp.109.027565

1University of Sheffield

Correspondence to Sean A. Spence

(s.a.spence@sheffield.ac.uk)

\begin{abstract}
Summary Deception is commonplace and a discipline such as psychiatry, so often reliant upon subjective accounts, may be susceptible to its effects (especially in the fields of military, liaison, medico-legal and forensic practice). However, psychiatric trainees receive little formal teaching on the subject of medical deceit. Here, I review some recent books on deception, emphasising those works that cast tangential light upon everyday psychiatric practice. Useful sources of reference include those concerning the philosophy of deceit, the recent rise of political lying and the clinical problem of feigned illness. A clinically helpful distinction emerges: that between truth (accuracy) and truthfulness (sincerity).
\end{abstract}

Declaration of interest S.S. contributed a chapter to one of the books reviewed.
Deception is the deliberate attempt by an agent to create what they think is a false belief in the mind of another (their victim). Telling a lie (making a knowingly false statement) is one mode of deceit but deception can also be achieved while literally stating the 'truth'. Many books have been devoted to this topic. Here, I review some recent publications that may inform aspects of psychiatric practice.

\section{Philosophical accounts of deception}

An interesting place to start is with the philosopher Bernard Williams' Truth and Truthfulness. ${ }^{1}$ In it, Williams articulates one of the apparent contradictions inherent in modern intellectual discourse, particularly as it influences the humanities: on the one hand, there is a pervasive suspicion of the concept of 'truth', the notion that there might be a verifiable factual answer to the problems we encounter (a legacy of suspicion, partially attributable to postmodernism; running counter to scientific progress); on the other hand, there also seems to be a suspicion that those in power are withholding the 'truth' from 'us'. So, how may society's commentators apparently doubt the existence of 'truth' while simultaneously feeling excluded from that which they doubt? The answer, proposed by Williams, lies in the distinction between truth (i.e. 'accuracy') and truthfulness (i.e. 'sincerity'). In other words, there is a difference between the 'facts' of a case and the testamentary intentions of an informant. As we shall see, this is a distinction to which we commonly resort in clinical psychiatry (i.e. the difference between whether a datum is 'true' and what it is that our informant intends when they recount it).

So, to take one of Williams' examples, if a woman (let us call her Nikita) tells her current partner (let us call him Honest John) that her former partner (Simple Simon) is now 'seeing someone' this may be an entirely true (accurate) statement. Factually, Simon is indeed seeing someone. However, we might imagine that John would be disappointed to discover that the 'someone' Simon is seeing is actually Nikita! Has Nikita told a lie? No: she has not uttered a false statement; her words were accurate. Nevertheless, in the context of their relationship, we might have expected her to tell John that she is the one seeing Simon. Hence, the deficit is one of truthfulness (sincerity); Nikita has not lied but she has been 'economical with the truth'. This is the sort of obfuscation traditionally associated with political discourse: a politician may not 'lie' but he avoids telling the 'truth': he may speak at a tangent to his interviewer, repeat non sequiturs and change the definition of certain words (e.g. 'I did not have sexual relations with that woman'; here, the informant famously chose not to equate fellatio with sex).

\section{Speech truth content}

What a truthful individual and a liar share is a central concern with the truth (the facts as they currently understand them). In order to be truthful, one must 'know what one is talking about'; in order to deceive, one must know what it is that one wishes to conceal. It is their relative truthfulness that distinguishes the honest informant from the liar. Conversely, there may be instances when a speaker is not primarily concerned with facts, where all he wishes to do is to manipulate his listener, speaking without regard to the truth content of his speech. This is what the philosopher Harry Frankfurt calls 'bullshit'. ${ }^{2}$ One encounters it whenever people are discoursing upon subjects of which they are ignorant. Frankfurt emphasises how much political speech is essentially bullshit and he warns also that numerous media outlets inevitably elicit bullshit from uninformed people asked to comment upon things they do not understand. Much 'opinion' is unencumbered by factual knowledge. Sadly, psychiatry is also vulnerable in this regard: with a paucity of objective data and with so much of what we discern consisting of subjective judgements, clinicians may come adrift if they do not adequately interrogate their material; think of ward rounds and team meetings where staff do not know their patients, where key-workers have been on leave or 
'on nights', where patients have not been clerked or examined, or co-informants contacted; so much of what passes for 'information' under such circumstances is little more than hearsay: phenomenologically, it comes perilously close to Frankfurt's notion of bullshit.

If we return to Williams then we encounter his insistence that a responsible person actually has an obligation to probe the grounds of their factual knowledge. ${ }^{1}$ In other words, if I am to be a reliable informant, I should give serious consideration to how accurate my 'truth' is: it may be polite (and apparently 'helpful') to concur with the tourist that 'Yes, the psychology department is opposite the abattoir' when proffered that suggestion, but it is dishonest to do so if I do not really know. I have a duty to my interlocutor (and myself) to take truth (accuracy) seriously.

\section{Self-deception}

Such a concern with what we are prepared to accept as true brings us to the thorny topic of 'self-deception'. How may a person come to believe something they 'know' to be untrue? Williams' approach is to suggest that they have failed to adequately question their own knowledge; they may be lazy, they may be cowardly, they may not wish 'to go there'. In the earlier example, Not-So-Honest John may have tacitly chosen not to cogitate upon Nikita's fidelity; he may have 'turned a blind eye'. Similarly, Not-So-Simple Simon may have chosen not to consider what Nikita is doing when she is not with him. In his classic account, Self-Deception, Herbert Fingarette posits that the central problem is one of disavowal: we deny that which we cannot accept, which we 'don't want to know'. ${ }^{3}$ However, the responsible person, the authentic agent, must examine herself and avow (accept) all that she knows. One can only begin to know oneself if one is prepared to honestly examine the 'facts'., One must never turn a blind eye.

\section{Truth and truthfulness}

The distinction between truth (accuracy) and truthfulness (sincerity) is implicit whenever psychiatrists attempt to distinguish delusional beliefs from lies, as in malingered or 'instrumental' insanity. In the first instance we construe the belief to be false (delusional) and the informant sincere; in the second, we cannot really access the belief as we judge the informant to be insincere, dishonest. In the Ganser syndrome, a prisoner may tell us that humans have 3 legs, cows have 5 and that there are 13 months in the year; it is the persistent proximity of his 'errors' to the truth that serves to impugn his truthfulness (he seems too accurate to be genuinely mistaken). However, as we shall see, our human ability to detect deceit is actually rather limited.

\section{Political deception}

The Rise of Political Lying by the journalist Peter Oborne charts the disappearance of truth from political speech in Britain, from the Thatcher-era Tories' engagement of advertising gurus (ushering in our modern obsession with sound bites and managed communication), through the sleaze and self-interested lying of prominent members of the Major-era Tory party, and on into the disintegration of public trust which has accompanied the New Labour project, with its emphasis upon spin. ${ }^{4}$ What distinguishes
Oborne's account from a great many other polemics is its reliance upon empirical data: the published details of what was said in press releases, interviews, Parliamentary speeches and broadcasts. The advantage of such scrupulous attention to detail is that one may follow a timeline of mendacity: from the first recorded telling of a lie, through the blustering elaborations of that same falsehood, to the subsequent, equally bullish denials that any such statements were made. One advantage of reading a plethora of lies in succession is that one learns the styles of deceit deployed by key players: one famous spin doctor denies ever having said the things he said, despite their being on record; another does not deny what he said but denies that he meant it 'in that way'. Then there is an ex-prime minister whose habitual line of defence is that he initially said "what he believed'. The last represents something of a joker in the pack: how can one possibly question the sincerity of someone who declares that they said what they believed? Here, we reprise Williams' argument: a speaker not only has a duty to be sincere (truthful) but also to examine the basis of his beliefs, his facts (his truth). ${ }^{1}$ If he simply ignores the facts then he is speaking Frankfurtian bullshit. ${ }^{2}$

\section{The psychology of deception}

Of course, politicians have several advantages over their audiences, not least the human propensity for believing what we are told: we share a common 'truth bias', in that we tend to assume that our informant is honest. Combined with a deception detection rate that is little better than chance (or $50 \%$; meta-analyses reveal accuracies in the region of $54 \%),{ }^{5}$ we are prone to being duped. Fortunately, the social and behavioural psychology of human deceit has recently been re-reviewed in Aldert Vrij's Detecting Lies and Deceit (a work drawing on more than 1000 sources). ${ }^{6}$ The 'take home' messages from this vast volume are the following: we lie frequently, often for altruistic or at least socially cohesive ends ('Professor, your paper was brilliant'); the rules of thumb by which we identify liars ('they avoid eye contact', 'they fidget') are inaccurate and hazardous when deployed in the legal arena (to denote 'guilt'); professional lie detectors (e.g. police and customs officials) evince greater confidence in their detection skills than lay people, confidence that is empirically unfounded; and the various technological means of lie detection reported in the media (while noticeably absent from the peer-reviewed scientific literature) are over-sold. Vrij's book is a tour de force, placing lie detection on a solid scientific basis.

\section{The psychiatry of deception}

Are there any lessons here for psychiatry? Well, yes there are: we should be especially cautious when attributing deceit to others, for we may very well be wrong. Also, we are wiser acquiring verifiable, objective data than espousing illinformed opinions. It is important to keep an open mind. Nevertheless, there is no avoiding the fact that sometimes we must countenance deceit. Fortunately, several authors have tackled these issues head on: three books are of interest.

Perhaps the most ambitious in scope is Charles Ford's Lies! Lies! Lies!, ${ }^{7}$ a clinician's text that assays an immense 
literature, from animal studies and the acquisition of deceptive skills by children, to the 'normal' lying encountered in everyday life and the pathological scenarios played out by certain personality types. There are fascinating chapters on imposture, false accusations and confessions, and Ford is particularly strong on canonical psychodynamic accounts of deception (spanning most of the 20th century). He focuses, in particular, upon the four Cluster B personality disorders (antisocial, histrionic, borderline and narcissistic) and the obsessive personality (from Cluster C), arguing that they are especially associated with deceptive behaviours, although these vary phenomenologically: while the person with antisocial personality fabricates for gain and the person with histrionic personality tells extravagant stories to attract attention, the person with obsessive personality is more likely to deceive by providing partial truths, creating a false impression by imparting selected items of information. Ford's book provides a broad introduction to the clinical issues raised by deceit. He is also (mostly) sympathetic to the deceiver, suggesting that there is more to be gained by working with the behaviour than confronting or rejecting its exponent.

\section{Feigning illness}

In Playing Sick? Marc Feldman focuses primarily upon factitious disorder and its most extreme expression, Munchausen syndrome. ${ }^{8}$ His book also contains numerous clinical vignettes and has the added distinction of his having managed to elicit confessions from patients who have enacted such behaviours. Feldman emphasises the void that seems to lie at the heart of such conduct: it really can appear 'unbelievable' and seemingly without personal gain. Throughout, the standard psychiatric distinctions apply: in factitious disorder the motive, in so far as it may be hypothesised, is an unconscious desire for nurturance (often in the context of a borderline personality structure), whereas in malingering the motive is consciously accessible, for example the avoidance of military service. The latter may be 'normal' or antisocial in aetiology.

So, if we follow a path from factitious disorder (intangible gain) to malingering (tangible benefit), then we eventually reach a quagmire of issues embroiling military, liaison, medico-legal and forensic psychiatrists: from the dereliction of duty, through benefit fraud and exaggerated compensation claims, to the avoidance of prison or legal proceedings. Malingering is not a medical diagnosis but it does exist as an unwelcome shadow at the periphery of our discipline. Indeed, the problem, confined for centuries to military settings, seems only to have acquired civilian medical significance with the emergence of workers' health insurance and disability provisions at the turn of the 19th/20th centuries. ${ }^{9}$ Latterly, since the 1970s, highincome countries have funded a tripling of disability payments: mainly for subjective disorders lacking demonstrable organic pathology (e.g. back pain), in marked contrast to overall improvements in public health. How can this be so? An extended meditation upon this question is found in Malingering and Illness Deception, edited by Peter Halligan, Christopher Bass and David Oakley. ${ }^{9}$ Across 27 chapters, multiple authors from many different disciplines explore malingering in all its many guises. What may we conclude? Well, while psychiatrists and general practitioners can appear rather indulgent of medical deception, often choosing to rationalise or interpret such behaviour, fraud investigators, disability assessment physicians, psychologists and insurance analysts are rather less accommodating! Conversely, lawyers often choose to simply sidestep the issue altogether, advising medical witnesses to do likewise: it is not the legitimate function of a doctor to diagnose malingering as it is not a medical diagnosis and it is preferable for doctors to confine themselves to matters of fact. Does the patient's presentation fit a recognised medical diagnosis or does it not? It is for the court to decide whether the appellant is unreliable. ${ }^{9}$

Nevertheless, there is an elephant sitting in the psychiatrist's consulting room when it comes to malingering: the problem of consciousness itself. For, once one has admitted the possibility of unconscious motives and mechanisms, then how may one objectively distinguish malingering from factitious disorder (or hysteria or many other functional syndromes)? The inconvenient truth is that we cannot know what our patient is thinking (consciously) and neither can anyone else.

\section{A simple intervention}

Given the inherently subjective nature of much of psychiatric discourse, it can seem as if there is no remedy to the problem of covert deception. Nevertheless, we might adjust our practice in relatively simple ways in order to cope. One suggestion might be to increase the opportunity for reflective practice whenever teams meet to discuss patients. Such meetings might conclude with consideration of the following simple questions: What have we learnt that we did not know before? How compelling is the evidence that we have considered? Are there any weaknesses in our account? What steps might we take to most accurately clarify our uncertainties? Which steps would most swiftly benefit our patient and their carers? These questions might serve to rapidly identify those areas where our information is most deficient.

\section{Conclusions}

Deception is ubiquitous although it need not be illintentioned; often it seems to lubricate the wheels of human social interaction. Nevertheless, losing sight of the truth carries dire consequences for individuals, relationships and societies. Drawing a distinction between truth (accuracy) and truthfulness (sincerity) may be of assistance in clinical psychiatry, not least because it maps so well onto important phenomenological distinctions (e.g. those between delusions and feigned insanity, hysteria and malingering). A discipline such as psychiatry, reliant as it is upon subjective data, places an especial obligation upon practitioners to constantly interrogate the truth content (accuracy) of what it is that they say, especially when describing patients.

\section{Acknowledgements}

I thank the referees for their comments. Also, over the past decade or so, my understanding of this area has benefited greatly from discussions with 
the following investigators, to whom I am most grateful: Christopher Bass, Per Anders Granhag, Peter Halligan, Jose Villagran and Aldert Vrij.

\author{
About the author \\ Sean A. Spence, MD, FRCPsych, is Professor of General Adult Psychiatry at \\ the University of Sheffield, UK.

\section{References} \\ 1 Williams B. Truth and Truthfulness. Princeton University Press, 2002. \\ 2 Frankfurt HG. On Bullshit. Princeton University Press, 2005. \\ 3 Fingarette H. Self-Deception. University of California Press, 2000
}

4 Oborne P. The Rise of Political Lying. Free Press, 2005.

5 Bond CF, De Paulo BM. Accuracy of deception judgements. Pers Soc Psychol Rev 2006; 10: 214-34.

6 Vrij A. Detecting Lies and Deceit: Pitfalls and Opportunities (2nd edn). Wiley, 2008.

7 Ford CV. Lies! Lies! Lies! The Psychology of Deceit. American Psychiatric Press, 1999.

8 Feldman MD. Playing Sick? Untangling the Web of Munchausen Syndrome, Munchausen by Proxy, Malingering, and Factitious Disorder. Routledge, 2004

9 Halligan PW, Bass C, Oakley DA. Malingering and Illness Deception. Oxford University Press, 2003

\title{
New Ways of Working is dead, long live New Ways of Working! Revised joint guidance on the employment of consultant psychiatrists
}

\author{
Andrew Clark
}

The Psychiatrist (2010), 34, 149-150, doi: 10.1192/pb.bp.109.025551

${ }^{1}$ Greater Manchester West Mental Health NHS Foundation Trust

Correspondence to Andrew Clark (Andrew.Clark@gmw.nhs.uk)

\begin{abstract}
Summary In 2005 the Royal College of Psychiatrists, the NHS Confederation, the National Institute for Mental Health in England and the Department of Health jointly produced the first edition of the Joint Guidance on the Employment of Consultant Psychiatrists. This was integral to the New Ways of Working initiative and outline different professional roles within mental health services. Four years on the document has been extensively revised. The new 2009 edition emphasises achieving viable and satisfying consultant posts through effective job planning and good team functioning. It also contains guidance on recruitment processes with useful examples of templates, flowcharts and good practices.
\end{abstract}

Declaration of interest A.C. was part of the Joint Working Group responsible for reviewing and rewriting the Joint Guidance on the Employment of Consultant Psychiatrists, March 2009.

\section{Changes to mental health services}

Mental health services and the role of the consultant psychiatrist within services have both changed radically over the past decade. At the heart of these changes has been the National Institute for Mental Health in England (NIMHE) National Workforce Programme and its initiative New Ways of Working. The phrase 'new ways of working' has become a mantra chanted equally loudly by both its proponents and opponents to encapsulate all that has been seen as good or bad about those changes. The National Workforce Programme and the formal New Ways of Working initiative both came to an end in March 2009, with a closing conference 'Moving on to a creative capable workforce'.

As part of that conference, a number of key documents setting out the future direction for mental health services and workforce were published. Included within those documents was a revision of the Joint Guidance on the Employment of Consultant Psychiatrists, ${ }^{1}$ which was first issued in $2005 .^{2}$ What does it say and how different is it to what went before?

\section{The red book and beyond}

Prior to the 2005 publication, the Royal College of Psychiatrists used to issue its own guidance, informally known as 'the red book'. ${ }^{3}$ This laid out model job descriptions for consultant posts and included recommended' levels of consultant staffing and 'irreducible minimum' levels of consultant staffing by reference to catchment populations. These levels were, however, rarely achieved and were seen by others as unrealistic and idealistic. The College, NIMHE, the National Health Service (NHS) Confederation, and the Department of Health collaborated to produce the 2005 joint guidance, which had a much wider acceptance and credence. It retained the numbers within it but downgraded them to indicators and signalled an intention of 'moving from a reliance on 